\title{
O BIG DATA COMO FATOR DE DESEQUILÍBRIO À LIVRE CONCORRENCIA ${ }^{1}$
}

THE BIG DATA AS AN IMBALANCE FACTOR TO FREE COMPETITION

Felipe Augusto dos SANTOS ${ }^{2}$

Ana Paula Bagaiolo MORAES ${ }^{3}$

ISSUE DOI: $10.21207 / 2675-0104.2018 .784$

\begin{abstract}
RESUMO
A massificação do acesso à Internet permitiu um maior fluxo de informações, configurando-se a economia digital, com destaque para intensa produção de dados, principalmente pessoais. Com a maior disponibilidade de dados, surgem as tecnologias e métodos aptos a operá-los. Nesse cenário advém o Big Data, produto da combinação de volume, velocidade e variedade na operação de dados, que possibilita a extração de valor de tais dados, constituindo um lucrativo mercado. Contudo, esse mercado do Big Data possui falhas, sendo necessária a intervenção estatal, por meio do Direito Concorrencial, para manter equilibrado o ambiente concorrencial.
\end{abstract}

Palavras-chave: Big Data; Direito Concorrencial; livre concorrência; proteção ao consumidor; privacidade

${ }^{1} \mathrm{O}$ presente artigo sintetiza a monografia de conclusão da pesquisa, realizada para o Programa Interno de Bolsas de Iniciação Científica (PIBIC 2017-2018) da Faculdade de Direito de Franca (FDF), Franca/SP.

${ }^{2}$ Discente da Faculdade de Direito de Franca (FDF), Franca/SP. Bolsista do Programa Interno de Bolsas de Iniciação Científica (PIBIC 2017-2018).

${ }^{3}$ Doutora em Direito Político e Econômico pela Universidade Presbiteriana Mackenzie (2018), Mestre em Direito Internacional pela Universidade Estadual Paulista Júlio de Mesquita Filho (2011), Especialista pela Fundação Armando Álvares Penteado em Direito do Agronegócio (2010) e Graduada pela Faculdade de Direito de Franca (2008). Atualmente é professora e atua nas áreas de Direito Civil (com ênfase em Parte Geral, Obrigações, Família e Sucessões) e Direito do Agronegócio, com projeto de pesquisa sobre os impactos do RenovaBio na região de Ituverava/SP pela Faculdade Dr. Francisco Maeda (FAFRAM). 


\begin{abstract}
The massification of the Internet access allowed a greater flow of information, configuring the digital economy, with emphasis on the intense production of data, mainly personal. With greater availability of data, the technologies and methods capable of operating them emerge. In this scenario comes Big Data, product of the combination of volume, velocity and variety in data operation, which enables the extraction of value of such data, constituting a lucrative market. However, this Big Data market has flaws, requiring state intervention, through competition law, to keep the competitive environment balanced.
\end{abstract}

Keywords: Big Data; Competitive Law; free competition; consumer protection; privacy.

\title{
INTRODUÇÃO
}

A evolução tecnológica é capaz de ditar os caminhos que a sociedade seguirá como já ficou demonstrado na história pelo que representou a Revolução Industrial, a descoberta da energia elétrica, do petróleo, entre outras descobertas que propiciaram alterações socioeconômicas que conduziu ao atual estágio em que vivemos. Por ser contínuo o aperfeiçoamento tecnológico, permite-se que continue atualmente surgindo novas tecnologias capazes de alterar a ordem, tanto social quanto econômica.

Seguindo essa lógica, o desenvolvimento e a massificação do acesso Internet acompanhado nas últimas décadas, proporcionaram a criação de um novo ambiente apto a ser palco de uma nova revolução, chamada de Revolução 4.0 ou Revolução Digital. As informações, agora, são trocadas em tempo real, em decorrência da ampla gama de dispositivos capazes de se conectar a Internet, chamada de Internet das Coisas (Internet of Things) oferecendo maior mobilidade à conexão.

Por essa razão, na última década, se destacam as empresas que atuam com as chamadas inovações disruptivas, que não somente são responsáveis por provir novos mercados e modelos de negócio, rompendo com os antigos modelos de negócios, sendo empresas capazes de alterar o comportamento da população, seus hábitos de consumo, alterando a demanda.

O intenso fluxo de informações geradas através da Internet provém dos dados, que uma vez processados resulta em informações, muitas vezes em estado bruto que representa um dos principais fatores de alteração socioeconômica vivenciada pela sociedade nos dias atuais, pois isso permite as empresas a operar com o chamado Big Data, que é constituído pela combinação de quantidade altíssima de dados, seguindo 
os requisitos de velocidade, variedade e volume, que se convertem em valor.

Essa alteração representa um fato novo para o ambiente concorrencial, na medida em que a posse de tais informações levem às empresas a novos modelos de negócios, e deles emergir novas possibilidades de práticas anticoncorrenciais, como cartel, abuso de posição dominante, cláusulas abusivas, entre outras.

Tais características tornam, portanto, do desenvolvimento de um mercado orientado por dados insurgirem questões relacionadas ao Direito Econômico para a manutenção do ambiente de livre concorrência.

\section{A ERA DO BIG DATA}

A inovação tecnológica que a sociedade vivencia na atualidade tem provocado efeitos que abrangem tanto no aspecto social quanto econômico, por intermédio da revolução digital que é estimulada pela quantidade cada vez maior de dispositivos pessoais conectados à Internet e equipados com sensores digitais, a chamada Internet of Things (IoT). Nessa realidade aumenta-se o fluxo de dados disponíveis, emergindo um novo modelo de negócios pautados na informação e a possibilidade desses influenciarem nas tomadas de decisões.

O autor Vicente Bagnoli (2016, p. 7) compreende esse atual momento como uma Era do Big Data, pois os números de crescimento econômico são altos e as consequências para a sociedade são tamanhas que não faz discriminação entre ricos e pobres, além disso, o horizonte para a aplicação dos dados podem guiar benefícios ao consumidor, e até mesmo salvar vidas e evitar ataques terroristas.

A sociedade, atualmente, experimenta os efeitos da Revolução Digital, principalmente, principalmente pelo aperfeiçoamento e massificação do acesso à Internet, a principal plataforma para o desenvolvimento de novas formas de mercado, de comunicação, de trabalho, de construção de relacionamentos etc., posto que, conforme citado em publicação da $\operatorname{OCDE}(2013, \text { p. } 7 \text {, tradução nossa })^{4}$, “(...) tem

\footnotetext{
${ }^{4}$ No original: (...) has a tremendous capacity to enable "crowd sourcing" of consumer and user data in ways that can increase civic engagement and help citizens and consumers in their day-to-day activities.
} 
uma tremenda capacidade de permitir o "crowd sourcing"5 de consumidores e usuário de dados de forma que ampliam o engajamento cívico e auxilia cidadãos e consumidores em suas atividades cotidianas".

Num espaço intensamente conectado, gera-se enorme fluxo de informações - mais precisamente de dados que são a soma de caracteres ou símbolos sob os quais as operações são desempenhadas por um computador ou outros dispositivos eletrônicos, que formam uma informação em formato digital que poderá ser armazenada e transmitida. $\mathrm{O}$ próprio smartphone é um grande fornecedor de dados, já que concatena em um só dispositivo a conectividade à Internet, os dados de geolocalização, os dados de acesso e utilização de aplicativos, geração de imagens, vídeos e sons, entre outros dados, principalmente de cunho pessoal, que são gerados no cotidiano das pessoas.

Havendo maior disponibilidade de dados, consequentemente, e diante da possibilidade de convertê-los em valor, houve o estabelecimento de uma economia baseada nos dados, uma economia digital, em que "a utilização de dados tem se tornado o caminho-chave para que uma empresa líder supere seus concorrentes" (BAGNOLI, 2016, p. 11).

Destarte, será verificada a movimentação do mercado em que haverá cada vez mais agentes buscando a utilização de dados em seus modelos de negócios, uns com maior intensidade outros com menos, porém, todos incentivarão que as pessoas, os usuários dessas plataformas a fornecerem mais dados, criando-se um ciclo de procura e fornecimento de dados que tende a aumentar nos próximos, é que se apresenta a era do Big Data.

\subsection{DEFININDO O BIG DATA}

Há ainda certa dificuldade sobre a definição de Big Data, que implica na inexistência de uma definição oficial. Num primeiro momento, encontra-se em dicionários a proposta de uma descrição genérica, conforme Cambridge Dictionary ${ }^{6}$ e o Oxford Dictionary ${ }^{7}$, em que Big Data

\footnotetext{
5 Processo de obtenção de necessários serviços, ideias ou conteúdo mediante a solicitação de contribuições de um grande grupo de pessoas e especialmente de uma comunidade online, em vez de usar fornecedores ou empregados tradicionais. Disponível em: <https://www.merriamwebster.com/dictionary/crowdsourcing>. Acesso em: 01 ago. 2018.

${ }^{6}$ Disponível em: <https://dictionary.cambridge.org/dictionary/english/big-data>. Acesso em: 01 ago. 2018.

${ }^{7}$ Disponível em: < https://en.oxforddictionaries.com/definition/big_data>. Acesso em: 01 ago. 2018.
} 
é um "extenso conjunto de dados que são produzidos pelas pessoas ao utilizarem a internet, e que somente podem ser armazenados, interpretados e utilizados com o auxílio de ferramentas e métodos especiais".

Contudo, ressalta Gil Press (2014), o grande desafio que é definir Big Data, como no caso da empresa de consultoria McKinsey \& Company, que ao definir o Big Data, o faz, intencionalmente, de forma genérica, semelhante a que os dicionários citados fizeram ${ }^{8}$, posto que ao recobrir de subjetividade a definição, é capaz de associar essa definição às constantes alterações acerca de quão grande e vasto deve ser o volume de dados a fim de que possa ser considerado Big Data. Justifica-se tal preocupação ante a rápida evolução tecnológica que tem possibilitado que a cada ano aumente a escala de volume de dados, que de acordo com projeções da IBM, será criado até o ano de 2020, aproximadamente 40 zettabytes de dados, um aumento trezentas vezes quando comparado com o volume criado até $2005^{9}$.

O autor Vicente Bagnoli (2016, p. 8) se refere ao Big Data como "um conjunto gigante de dados contraído por empresas, governos e organizações, os quais são amplamente analisados através de algoritmos".

Contudo, a definição de Big Data deve abarcar, além de suas características, os meios e métodos necessários para sua conversão em valor. Dessa maneira tem-se a seguinte definição: "Big Data é a posse de recursos de informações, caracterizada pelo grande volume, velocidade e variedade, que exige Tecnologia e Métodos Analíticos específicos a fim de transformá-la em Valor" (DE MAURO et al., 2016, p. 131, tradução nossa $)^{10}$.

Assim, partindo desse princípio, de que são necessários o usos de tecnologias e métodos analíticos específicos para o Big Data, é que se passará a análise de suas particularidades.

\subsubsection{OS "VS" DO BIG DATA: VOLUME, VELOCIDADE E VARIEDADE E VALOR}

\footnotetext{
8 "Conjuntos de dados que o tamanho ultrapassa a habilidade típica das ferramentas de software de bancos de dados para capturar, armazenar, administrar e analisar" (MCKINSEY apud PRESS, 2014). ${ }^{9}$ Disponível em: < http://www.ibmbigdatahub.com/infographic/four-vs-big-data $>$. Acesso em: 09 mai. 2018.

${ }^{10}$ No original: The Big Data refers to a giant set of digital data held by companies, governments and organizations which analyzes extensively through algorithms
} 
Os três "V's" representam a atribuição de características mais habitual do Big Data. O primeiro "V" representa volume e está relacionado à principal característica da era do Big Data, que é a grande quantidade de dados - e que ainda se demonstra crescente - que podem ser manipulados em decorrência dos avanços tecnológicos, principalmente como advento da Internet das Coisas. Dessa maneira, esse primeiro atributo representa a enorme escala na geração e a coleta de dados, que conforme dito, não será quantificada, visto que a capacidade aumenta com o desenvolvimento tecnológico.

De acordo com os dados de expectativa de crescimento apresentados anteriormente no texto, com vistas à perspectiva de evolução da tecnologia utilizada na coleta e análise de dados, nota-se que a unidade de medida utilizada atualmente já é o zettabytes, que representa a 1 sextilião ou $10^{21}$ de bits - porém num futuro próximo, é possível que já estejam sendo calculados o yottabyte, que representa $10^{24}$.

Já a velocidade está relacionada com a rápida geração e processamento de dados, potencializando a capacidade de esses dados serem úteis, principalmente quanto às utilizações comerciais e a identificação de padrões e tendências, fazendo-se uso de uma produção muito mais contínua, do que era feito anteriormente.

Por fim, a variedade de dados está ligada à possibilidade de operar com dados oriundos de diferentes fontes. Nesse sentido, os dados se dividem em estruturados e os semi-estruturados e os desestruturados, conforme explica Bagnoli (2016, p. 8, tradução nossa) ${ }^{11}$ que os “'(...) dados gerados a cada segundo podem ser dados estruturados, que são os padrões estritos pré-estabelecidos, ou dados desestruturados (...) aumentando cada vez mais a exposição de privacidade, informação empresarial e segredos de Estado".

Busca-se, ao lidar com enormes montantes de dados, originados de diversas formas e de diferentes fontes, de maneira veloz, a obtenção de valor, que justifica todo o esforço no aprimoramento tecnológico buscado, principalmente, por empresas.

Há quem considere haver outros dois "Vs" nessa qualificação, a veracidade e a validação, como explica Bagnoli (2016, p. 9), que aquela é a confiabilidade de que os dados obtidos condizem com a realidade, obtendo informação mais apurada, enquanto essa é a habilidade de

\footnotetext{
${ }^{11}$ No original: (...) The data generated every second can be structured data, those with pre-established strict standards or unstructured data, (...) become increasingly the exposure of personal privacy, corporate information and secret of States.
} 
assegurar que os dados oriundos de diversas fontes possuem sentido, quando agrupados.

Quanto ao valor, trata-se da orça motriz do Big Data, sendo o principal objetivo de quem atua nesse mercado. Situa-se, dessa maneira, ao lado das três principais particularidades do Big Data.

O potencial valor do Big Data, que move o intenso crescimento desse mercado, o faz ser comparado com a nova corrida do petróleo ${ }^{12}$, que se justifica, conforme aponta Chen et al. (2014, p. 5), uma pesquisa da consultoria McKinsey que afirma que a aplicação do Big Data fosse utilizado de maneira efetiva, no âmbito das empresas do setor da saúde, para melhorar a eficiência e a qualidade os ganhos ultrapassariam 300 milhões de dólares.

Contudo, para que se tenha a obtenção de valor dessa utilização dos dados, é necessária a construção de sua cadeia de valor, que nada mais é que uma ferramenta utilizada para analisar o encadeamento de sucessivas atividades que guiam a geração de valor de um produto ou serviço. No âmbito do Big Data, a cadeia de valor é ditada pelo "(...) fluxo da informação é definido por uma série de etapas necessárias para a geração de valor e insights úteis dos dados (...).” (CURRY, 2016, p. 31, tradução nossa $)^{13}$.

Portanto, é ao final desse processo que se tem a composição do que seria apenas um grande montante de dados, transformado em algo de valor e relevante socioeconomicamente tanto para empresas e organizações privadas quanto para entes públicos.

\section{A EXPLORAÇÃO ECONÔMICA DO BIG DATA}

A possibilidade que os avanços tecnológicos proporcionaram de operar com o Big Data, fez com que surgissem novos modelos de negócios baseado em dados, em que as empresas que nele atuam são reconhecidas como multi-sided platforms, pois reúnem usuários e anunciantes, posto que, os dados gerados pelo primeiro permitem a produção de anúncios direcionados de acordo com os perfis gerados, que visam proporcionar

\footnotetext{
12 The Economist, "The World's Most Valuable Resource Is No Longer Oil, but Data," 6 de maio de 2017. Disponível em: <https://www.economist. com/news/leaders/21721656-data economy-demandsnew-approach antitrust-rules-worlds-most-valuable-resource>. Acesso em: 01 ago. 2018.

${ }^{13}$ No original: (...) information flow is described as a series of steps needed to generate value and useful insights form data (...).
} 
melhores resultados econômicos ao segundo, porque haverá uma maior probabilidade de conversão em vendas ao anunciar um produto ou serviço para pessoas que estejam mais propensas a isso.

Conforme descreve Stucke e Ezrachi (apud OCDE, 2016, p. 16, tradução nossa) ${ }^{14}$ : “As empresas estão ampliando a adoção de modelos de negócios que dependem de dados pessoais como uma chave de entrada (...)".

Ao explorar economicamente o grande volume de dados, sugerese um tradeoff tipicamente do ambiente econômico, na qual o Big Data oferece tanto para os agentes capazes de operá-lo quanto para os anunciantes que contratam os serviços daqueles benefícios decorrentes do maior número de informações disponíveis. Contudo, ressalta Sloan e Warner (2013, p. 2), haver riscos inerentes à operação com esses dados, quanto à privacidade informacional, que é a capacidade de coletar informações sobre uma pessoa ou uma coletividade e o que fazem com esses dados. Sendo assim, ainda de acordo com os autores, é preciso nesse tradeoff equalizar os benefícios e os riscos.

Buscando tal equalização é necessário, primeiramente, conhecer o ecossistema do Big Data, que é descrito pela OCDE (2016, p. 12), como o ambiente no qual o "Big Data é coletado, transacionado e convertido em valores monetários em um complexo ecossistema composto por múltiplos mercados interconectados, muitos dos quais são multi-sided.".

O epicentro dessa estrutura apresentada são as plataformas, visto possuírem um modelo de negócios baseado em dados de seus usuários. Tais plataformas são distinguidas em duas categorias, conforme destaca a publicação da OCDE (2016, p. 12): plataformas chamadas de attention e de matching. A primeira é caracterizada pela oferta de serviços aos usuários sem a cobrança monetária pela sua utilização, todavia, a plataforma é subsidiada com os dados fornecidos por seus usuários que, portanto, pagam com sua atenção. Isso porque, uma vez estando na posse dos dados pessoais de seus usuários, as plataformas são capazes de direcionar melhor os anúncios a um determinado grupo de pessoas mais propensas a se tornarem consumidores de determinado produto e serviço; na mesma medida são também são capazes de aprimorar seus serviços, baseados em melhores feedbacks espontâneos de seus usuários, por ser uma forma mais orgânica de apuração de padrões e tendências.

\footnotetext{
${ }^{14}$ No original: Companies are increasingly adopting business models that rely on personal data as a key input (...).
} 
Por outro lado, difere-se das plataformas caracterizadas como matching, que se caracterizam por serem subsidiadas através do recebimento de mensalidades de acesso ou custos por transações realizadas dentro de sua infraestrutura.

A constituição de um ecossistema no âmbito do Big Data é essencial para o desenvolvimento de um mercado nesse sentido, visto que ele possibilita interações entre diversos setores da economia, sendo que de um lado se tem as plataformas que oferecem serviços aos consumidores ao mesmo que se apropriam de seus dados. Dessa forma, essas mesmas plataformas, são também capazes de oferecer serviços a outro público, o de anunciantes, por exemplo, que veem na plataforma uma maneira de otimizar resultados com os anúncios melhor direcionados.

\subsection{O MERCADO DO BIG DATA}

Uma vez que se configura o ecossistema do Big Data, propício a altos índices de trocas de dados e valores entre os atores que o integram, é constituído um mercado ${ }^{15}$, visto esse ser inerente àquele, pois necessita das transações que são realizadas nesse ambiente para existir, necessita haver uma oferta e demanda.

A melhor maneira de verificar o Big Data é através de seu mercado relevante, por tornar possível a compreensão da forma com a qual se estrutura determinado mercado em toda sua amplitude, verificando os pontos estruturais da concorrência nesse específico mercado, conforme o entendimento Vicente Bagnoli (2016, p. 11, tradução nossa) ${ }^{16}$ ao afirmar que: "O objetivo proposto pela definição do Mercado Relevante do Big Data (ou simplesmente BDRM) é proporcionar a visão macro deste mercado em seus diferentes estágios (...)".

Reforça esse entendimento Graef (2015, p. 489, tradução nossa $)^{17}$, reconhecendo que "(...) O mercado relevante de um produto inclui todos os produtos e serviços o quais são considerados substitutos

\footnotetext{
${ }^{15}$ No âmbito econômico, é caracterizado como mercado a estrutura organizada que permite a atuação de compradores e vendedores, relacionando-se entre si e executando transações de valor e trocando informações ao redor do mundo através de meios de comunicação.

${ }^{16}$ No original: The goal of the proposed definition of the Big Data Relevant Market (or simply BDRM) is to give the whole picture of this market on its different stages (...).

${ }^{17}$ No original: (...) The relevant product market includes all products or services which are regarded as substitutes by consumers on the basis of their characteristics, prices and intended use (...).
} 
pelos consumidores com base em suas características, preços e intenções de uso (...).”.

Essa visão mais ampla do mercado preenche muito bem as necessidades que o estudo da exploração econômica do Big Data exige, isso porque, a utilização de grandes montantes de dados se espalha rapidamente para diferentes setores da economia, aumentando constantemente seu valor, exigindo imediato acompanhamento do conhecimento de seus impactos.

Ressalta-se que o item mais valioso da exploração econômica do Big Data são os dados de caráter pessoal, visto que a partir dos avanços tecnológicos permitiu que esse gênero de dados possibilitasse a aplicação anúncios melhor direcionados, verificar as tendências e provisionar as expectativas de mercado etc. Por essa lógica é possível realizar a seguinte classificação dos dados pessoais quanto à forma de mineração, proposta por Graef (2015, p. 475-476), que distingue, de um lado, os dados que os próprios usuários produzem, chamados de dados voluntários, como informações de perfil, fotos, lista de amigos etc. Por outro também existem os dados obtidos por meio de análise de comportamento a partir de ferramentas criadas pelos próprios provedores, chamados de dados observados. Há também uma terceira categoria, chamada de dados inferidos, que surgem da análise de informações voluntárias ou observadas.

Contudo, o mercado do Big Data se insere num cenário maior, que é o da economia digital, estabelecida na atual conjuntura da Revolução 4.0 .

\subsubsection{ECONOMIA DIGITAL}

A economia digital é caracterizada, por Vicente Bagnoli (2016, p. 14), por seu forte crescimento, dinamicidade, surgimento constante de novos serviços, concentração de mercado com diversos players com posição dominante o desbalanceado crescimento de grandes empresas e dos empreendimentos menores e consumidores.

Esse atual período da economia, conforme a publicação da OCDE (2016, p. 6), tem seus prós e contras para a livre concorrência. De um lado, favorece o ambiente concorrencial a utilização de dados ao produzir inovações que beneficiam empresas e consumidores, porém, por outro lado, os efeitos de rede gerados pelo Big Data podem conduzir a um poder de mercado e vantagem competitiva. 
Nesse cenário econômico é que se desenvolvem novos modelos de negócios, criados já no período da Internet, sem impedir que modelos tradicionais de negócios também fossem impactados.

\subsubsection{MODELOS DE NEGÓCIOS}

Buscando-se adequar a essa atual realidade, as empresas, principalmente as nascidas após a popularização da Internet, desenvolvem modelos negócios próprios, que se diferem dos tradicionais.

O mais comum, conforme é apresentado por Inge Graef (2015, p. 476-477), é utilizado pela maioria de provedores online de ferramentas de busca e redes sociais, assim como as plataformas de e-commerce, e oferecem a seus usuários acesso gratuito a suas plataformas, para então angariar dados referentes aos perfis de interesse e comportamento online, e então disponibilizar melhores serviços de publicidade a interessados. Há, dessa maneira, conversão dos dados pessoais em moeda indispensável para compensar os provedores.

Nessa perspectiva, reafirma Kerber (2016, p. 10, tradução nossa $)^{18}$, " (...) que os serviços das ferramentas de busca e redes sociais não são "gratuitos", mas sim pagos com os dados com os dados e a privacidade dos usuários (...)".

Fica também evidente que nesse modelo de negócios a preocupação das empresas em garantir, constantemente, a ampliação de sua base de usuários, tornando atraente o oferecimento de serviços livres de mensalidades. Portanto, quanto mais um pequeno grupo de grandes empresas consolida sua posição dominante de mercado, afastando as demais que sejam pequenas ou médias, seja por praticarem um modelo de negócios inviável para essas ou então que deixa de ser atraente do ponto de vista econômico, estar-se-á favorecendo a constituição de um oligopólio em detrimento do bem-estar do consumidor, que se verá preso a poucas opções e diante de possíveis práticas abusivas.

\footnotetext{
${ }^{18}$ No original: (...) the services of search engines and social networks are not "free" but paid with the data and the privacy of the users (...).
} 


\subsubsection{EFEITOS DE REDE E BARREIRAS DE ENTRADA: RISCOS PARA O MERCADO CONCORRENCIAL}

Os efeitos de rede são entendidos como o fenômeno no qual um produto ou serviço adquire mais valor na medida em que mais pessoas o utilizam.

O receio quanto sua interferência no ambiente concorrencial equilibrado é o looping que em grande escala ele é capaz de gerar, que conforme explica Lassere e Mundt (2017, p. 90) configura como "efeito bola de neve" que reforça o desenvolvimento de empresas dominantes, sendo que essas, tendo mais usuários, haverá maior disposição de dados; com mais dados à disposição será possível oferecer melhores serviços que seus concorrentes; diante de serviços melhores, surgirão mais interessados em adquirir os serviços prestados por essa empresa, em detrimento de outras, da mesma forma, a oferta de serviços melhores para os usuários também irá atrair mais usuários do que os demais integrantes do mercado, reiniciando esse ciclo.

Nesse contexto que surgem as preocupações concorrenciais nesse novo mercado por ficar " (...) demonstrado que a concorrência entre plataformas pode ser dificultada em decorrência de amplos efeitos de rede diretos e indiretos entre os diferentes lados do mercado e economias de escala (...)" (KERBER, 2016, p. 9, tradução nossa) ${ }^{19}$.

Assim, à medida que uma empresa se destaca e começa a se distanciar de seus concorrentes, tem-se o processo de fortalecimento de uma posição dominante de mercado, ampliando as barreiras de entrada no mercado, desfavorecendo o ambiente concorrencial equilibrado.

Dessa maneira, na medida em que o acesso ou posse dos dados é importante para concorrer nesses modelos de mercados do Big Data, não os possuir pode representar uma barreira de entrada aos novos entrantes, que não serão capazes de competir em pé de igualdade quanto às ferramentas.

Destaca Rubinfield, (2017, p. 12-30) que as barreiras de entrada englobam toda a cadeia de valor, visto que essa tem principal relação com o ambiente concorrencial por ser ter em seu fluxo a construção de valor do Big Data.

\footnotetext{
${ }^{19}$ No original: the theory of platform (or multi-sided) markets has shown that competition between platforms can be difficult due to often large direct and indirect network effects between different market sides, and economies of scale (...).
} 
Salienta-se que as barreiras de entrada são mais complexas do que podem representar de início e, quando analisadas no contexto da cadeia de valor elas podem ser disseminadas nas suas diversas partes, inclusive, podendo ser combinadas umas com as outras. Isso faz com que, mesmo que se por um aspecto uma barreira se apresenta baixa, por exemplo, para a coleta de dados, não quer dizer, imediatamente, que se estará diante de um mercado com barreiras de entrada baixa, pois num contexto geral do mercado e somando-se com as outras barreiras presentes nas demais partes da cadeia de valor, achar-se-á diante de altas barreiras de entrada.

A análise concorrencial do Big Data deve ser feita de caso para caso, compreendendo as características de cada mercado dentro desse ecossistema, para que se aplique a melhor medida para a manutenção do ambiente concorrencial equilibrado e bem-estar do consumidor.

\section{O BIG DATA NO ÂMBITO DO DIREITO CONCORRENCIAL}

Para que haja um funcionamento ideal de um mercado, é necessária a existência de um ambiente concorrencial, sendo que um mercado sem livre concorrência gera consequências negativas para a sociedade como um todo.

Nesse, salienta João Bosco Leopoldino da Fonseca (2015, p. 318), a importância do Direito da Concorrência como epicentro de preocupação do Direito Econômico, porque garantindo a o direito e o dever de concorrer, assegurará o direito à livre iniciativa, assim como estimula a inovação e o primor pela qualidade e melhor preço, dessa maneira, o consumidor também é recompensado pelo direito de livre escolha.

O mercado do Big Data é passível de falhas, visto a capacidade de alguns agentes desenvolverem poder de mercado e exercer dominância deste ante os demais concorrentes, principalmente pelos efeitos de rede e pelas barreiras de entrada.

Dessa maneira, na medida em que há um fato novo que altere a ordem da estrutura social e econômica, como é o caso do Big Data, é necessário se atentar a aplicação das ferramentas desta seara do Direito.

\subsection{A PROTEÇÃO DO AMBIENTE CONCORRENCIAL}


O debate para a proteção desse ambiente, na era do Big Data circula, geralmente, em três áreas: a) dados como uma fonte de poder de mercado; b) dados, transparência de mercado e concorrência; e c) dados relacionados a condutas anticoncorrenciais.

Quanto ao primeiro ponto, leva-se em consideração a condição que, segundo Bruno Lassere e Andreas Mundt (2017, p. 90), o acesso ou posse dos dados é importante para concorrer nesses modelos de mercados atuais, em virtude de não possuí-los é possível, representar uma barreira de entrada a novos entrantes, que não serão capazes de competir em pé de igualdade quanto às ferramentas.

Nesse sentido, salienta a OCDE (2016, p. 17, tradução nossa) $)^{20}$ que na economia digital, “(...) as empresas competem pelo o mercado ao invés de competir no mercado, levando a resultados de 'vencedor leva tudo', como foi observado quando o Facebook conseguiu deslocar o Myspace como a rede social mais popular (...)".

Trata-se de um mercado incomum, que favorece os agentes que já possuem bastante dados, a possuírem mais. Por esse motivo, trata-se de um mercado que precisa ter as características contestáveis, favorecendo sempre a entrada de novos concorrentes.

O segundo fator abordado por Lassere e Mundt (2017, p. 90), relaciona-se com a transparência que os dados podem oferecer ao mercado, principalmente nas relações entre fornecedores e consumidores e, fornecedores e fornecedores, geralmente, resultando efeitos positivos à concorrência. Primeiramente para os consumidores, diante de uma maior transparência no mercado é reduzida as chamadas assimetrias de informações, ou seja, é possível que os consumidores comparem preços e realize pesquisa das avaliações de determinado fornecedor previamente. Essa situação possibilita intensificar a concorrência, principalmente relacionada a preço e qualidade e, consequentemente, beneficiar novos entrantes, por implicar numa diminuição aos custos de entrada do mercado. Por outro lado, nas relações entre fornecedores há possibilidade de se verificar condutas limitadoras de concorrência, principalmente se se tratar de mercado com alto índice de concentração, visto que uma transparência nos preços praticados pode acabar resultando numa situação de conluio.

Por fim, têm-se os dados relacionados às condutas anticoncorrenciais, que aborda a coleta e o acesso aos dados de forma que

\footnotetext{
${ }^{20}$ No original: (...) firms compete for the market instead of competing in the market, leading to 'winner takes all' outcomes, as it was observed when Facebook was able to displace Myspace as the most popular social network (...).
} 
podem ser utilizados para práticas anticoncorrenciais. Nessa perspectiva, destaca a OCDE (2016, p. 21-23), algumas condutas anticoncorrenciais, como a conduta exclusiva pela limitação de acesso à dados-chave, a configuração dos dados como elemento essencial de entrada em alguns mercados impossibilitando o acesso de empresa a esses mercados e, o crescimento na formação de cartéis digitais.

Caberá, dessa maneira, ao Estado munido das ferramentas de direito concorrencial, estabelecer o equilíbrio no mercado do Big Data.

\subsection{OUTROS LIMITES A UTILIZAÇÃO DO BIG DATA}

Ao passo que o Big Data apresenta elementos que torna factível a ofensa a direitos de maior escopo que a livre iniciativa, diferentes jurisdições em todo mundo buscam novas leis que melhor resguardem os direitos de seus cidadãos ante a captação, análise ou transferência de dados. Por esse motivo, exige-se a intervenção do Direito Concorrencial na regulação do ambiente concorrencial.

Destaca Vicente Bagnoli (2015, p. 630), que tanto da perspectiva dos cidadãos, como consumidores, quando do ponto de vista dos negócios, a manutenção da privacidade é elemento essencial para a manutenção do ambiente concorrencial equilibrado, isso porque quanto àqueles é óbvia a vedação a invasão de sua intimidade, já a esses, assegurará a proteção de informações confidenciais, como relatórios financeiros, segredos comerciais etc.

Nota-se, portanto, que na grande maioria das vezes a análise dos impactos socioeconômicos do Big Data não se restringirá a análise ambiente concorrencial propriamente dito, mas sim se avançando sob outros temas, como a proteção do consumidor e sua privacidade.

Assim, a análise do ambiente concorrencial do Big Data deve ultrapassar a vertente estritamente econômica. Trata-se de posicionamento que se aproxima ao entendimento da União Europeia na análise concorrencial, que, conforme destaca Roberto Pfeiffer (2010, p 126), por não "compreenderem a defesa da concorrência em seu fim único, mas por diversas metas tais como a integração comunitária, a proteção dos consumidores, o desenvolvimento econômico e a competitividade das empresas europeias.".

Destarte, a proteção do consumidor, em especial a proteção à privacidade de seus dados pessoais, tornam-se uma limitação ao uso do Big 
Data, mesmo que aos olhos da proteção ao equilíbrio do ambiente concorrencial, não sendo necessária haver um deslocamento de sua análise para, por exemplo, o âmbito da proteção ao Direito do Consumidor.

\subsubsection{A PROTEÇÃO AOS DADOS DO CONSUMIDOR}

O consumidor, tem atribuição fundamental no escopo do Direito Econômico, principalmente no que concerne a proteção da livre concorrência. Trata-se, como visto, de uma tendência, aplicada na União Europeia e que é seguida por diversos países.

Nos Estados Unidos da América é que se teve o aspecto de dotar a Comissão de Comércio com poderes para proteger o consumidor, conforme destaca Daniel Glória (2003, p. 34) a criação da Federal Trade Comission (FTC), em 1914, “(...) com o objetivo fundamental de aplicar as leis antitrustes e proteger os interesses dos consumidores (...)".

Seguindo tal tendência, o texto da Constituição Federal de 1988, ao ditar quais são os princípios gerais da atividade econômica, em seu artigo 170, em seus incisos IV e V, destacam, respectivamente, que para se atingir a ordem econômica e financeira é necessário observar tanto o princípio da livre concorrência como a defesa ao consumidor.

Nesse sentido, João Bosco Leopoldino da Fonseca (2015, p. 95) traduz a intenção do constituinte em compreender o consumidor como um dos elos da economia, e que sua proteção é um processo inerente à preservação e garantia da livre concorrência.

Seguindo, tal pensamento é sintetizado por Daniel Firmato de Almeida Glória (2003, p. 93), exclamando: “A proteção do consumidor é o princípio básico do direito da concorrência, pois se não houver concorrência não há uma efetiva defesa do consumidor. Em outras palavras, a empresa sem o consumidor não existe!”.

Destaca-se a inerência entre empresa e consumidor, não podendo desassociá-los quando da análise de mercado e de situações que venham a prejudicar seu desenvolvimento. Isso se repete no âmbito do Big Data, em que há maior quantidade de informações sobre os consumidores.

Tal posicionamento foi reforçado, recentemente, com a decisão da Bundeskartellamt (órgão alemão responsável por analisar práticas anticoncorrenciais), em abrir um procedimento investigatório contra o Facebook, por suspeita de a empresa ter imposto a seus usuários/consumidores a adesão de termos de serviço e condições de uso 
abusivas, principalmente com relação à concessão de dados pessoais, valendo-se, para tanto, de sua posição dominante no mercado ${ }^{21}$. Quanto a esse caso, o relatório da OCDE (2016, p. 21) destaca a fala do presidente da Bundeskartellamt, Andreas Mundt, que destaca a situação de abuso de poder de mercado e a desinformação dos usuários quanto aos dados que são coletados.

Entende-se que a proteção dos interesses do consumidoré um dos objetivos intrínsecos do direito concorrencial, tendo de ser levado em consideração nas análises de regulação concorrencial, entendimento esse que a Bundeskartellamt também demonstrou se alinhar.

Nesse sentido, é que o existente debate entre consumidor e proteção de dados não deve ser restrito somente no ponto de vista do consumidor, pois estaria restringindo a visão do tema, conforme destaca Vicente Bagnoli (2015, p. 631, tradução nossa) $)^{22}$ : “O debate deve se preocupar com o bem-estar do consumidor, especialmente com o viés concorrencial uma vez que a concentração econômica, via de regra, limita os agentes que competem no mercado, deixando os consumidores vulneráveis $(. .$.$) ".$

O que justifica a ação do direito concorrencial é a indicação da existência de uma posição influente da empresa, capacitando-a de impor práticas abusivas a um grande número de consumidores, o chamado consumidor abstrato, com objetivo de obter ainda mais poder mercado.

\subsubsection{A PRIVACIDADE DO USUÁRIO/CONSUMIDOR NA ERA DO BIG DATA}

Ao lado da proteção ao usuário/consumidor com o advento do Big Data, encontra-se a proteção à privacidade, outro importante limitador do acesso indiscriminado aos dados pessoais.

A proteção à privacidade dos dados do indivíduo passa a ser pertinente para a análise do ambiente concorrencial do Big Data, quando ganha contornos econômicos, fazendo com que sua violação é capaz de

\footnotetext{
21 Disponível em: <http://www.bundeskartellamt.de/SharedDocs/Meldung/EN/Meldungen \%20News\%20Karussell/2016/02_03_2016_Facebook.html>. Acesso em 9 de out. de 2017.

${ }^{22}$ No original: (...) The debate should be concerned with consumer welfare, especially with the competitive bias once the economic concentration, as a rule, limits the agents that compete in the market, thus making consumers vulnerable (...).
} 
garantir a empresa que o coletou um ativo capaz de fornecer vantagem competitiva de maneira ilícita, causando falhas no mercado.

Contudo, há um paradoxo na perspectiva da privacidade com relação ao Big Data, sendo que, apesar de haver o entendimento de que é necessária a proteção dos dados pessoais dos usuários das plataformas na economia digital, por outro, o comportamento desses indivíduos nessas plataformas não asseguram a proteção.

Conforme destaca Anita L. Allen (2016, p. 73), os indivíduos não são capazes de negociar, efetivamente, os "termos e condições" relacionados à sua privacidade, o que faz com que a proteção da privacidade informação deve ser realizada pelo próprio usuário, por se apresentar como uma tarefa viável, ao utilizar um ambiente privado para conversas, usar senhas em dispositivos eletrônicos, instalar software de segurança, moderar o uso de redes sociais, criptografar etc. Porém, mesmo com a aplicação dessas medidas, não se trata de uma proteção robusta a privacidade dos dados dos indivíduos.

Deve ser destacado, quanto à privacidade, que há entendimento diferentes no tocante à sua proteção na era do Big Data, isso porque, conforme afirma Wolfgang Kerber (2016, p. 3) o conceito de privacidade na União Europeia é de que se trata de um direito fundamental, tendo assim a ideia básica de que as pessoas devem ter controle sobre seus dados.

Contrapondo esse entendimento, salienta Anita L. Allen (2016, p. 76-78), em que um relatório da sede do governo federal dos Estados Unidos da América afirma que o Big Data ainda não representa uma ameaça que exija grandes agendas legislativas. Alguns críticos mais contundentes, afirmam que deve ser adotado um entendimento quanto à privacidade semelhante ao da União Europeia. Há também quem afirme que enquanto não houver a proteção da privacidade dos indivíduos no âmbito do Big Data, esse não atingirá seus objetivos. Por fim, o caminho sugerido pela publicação, no caso dos EUA, é o respeito aos princípios da transparência e a liberdade de escolha.

Já o contexto brasileiro se assemelha ao da União Europeia, tratando a também como direito fundamental, protegido por norma constitucional (art. 5 ${ }^{\circ}$ inciso X, do Constituição Federal de 1988). 
O Big Data é, atualmente, o principal elemento de desenvolvimento das empresas, tenham elas modelos de negócios tradicionais ou não, são evidentes os impactos que sua utilização provoca e continuará provocando. A utilização de dados pessoais para o mercado não é recente, sendo utilizados em menor escala há muitos anos. Contudo, destacam-se a versatilidade e a amplitude dos resultados advindos de sua utilização de dados em grande escalda.

Tais atributos do Big Data se devem, claramente, de suas características, uma vez que de um veloz processo de análise e processamento realizados por métodos e tecnologias cabíveis, permitem a conversão de um grande montante de variados dados, oriundos de múltiplas fontes, em informações relevantes - e também valiosas - para a identificação de padrões e tendências, através da coleta de dados que vão muito além dos pessoais (como nome completo, idade, endereço etc.), abarcando hábitos de navegação e interesses na Internet.

Foi visto com muito bons olhos pelo mercado o desenvolvimento tecnológico que propiciou o advento do Big Data por meio de sua cadeia de valor, tanto por agentes que lidam com diretamente com dados quanto os indiretos, pois além de permitir a realização de predições quanto à possibilidade de determinado evento vir ou não a acontecer, ser possível identificar com mais clareza as necessidades dos consumidores também se tornou possível o serviços de anúncios melhores direcionados aos indivíduos mais propensos em conversão em compras, trazendo melhores resultados financeiros.

Não obstante os benefícios proporcionados pelo Big Data, é sua performance econômica que merece e exige atenção, posto que, em decorrência dos valores que giram em torno de sua utilização, ele tem se tornado um ativo interessante para as empresas, que cada vez mais buscam criar ou adequar seus modelos de negócio para que haja maiores possibilidades de mineração de uma maior quantidade dados.

Numa busca pela exploração econômica dos dados pessoais, que tem se tornando constante no dia a dia de grandes empresas, esses têm sido convertidos em moeda. Isso se justifica pelo modo aplicado pelas plataformas, como ferramentas de busca e redes sociais, têm se utilizado para coletar dados dos usuários, que é por meio da disponibilização "gratuita" dos serviços da plataforma, contudo, o usuário que fica livre de cobranças de taxas pecuniárias paga com seus dados.

Essa prática é bastante comum nos serviços oferecidos pelas empresas já estabelecidas na era da Internet, conduzindo questionamentos 
sobre a atividade fim dessas empresas. Por exemplo, uma rede social que busque estabelecer, sem custos, contatos entre empresas com cargos vagos e profissionais que desejam a esses se candidatar, ou, nesse caso hipotético, a atividade fim seria a comercialização de espaço publicitário para grupos de ensino que desejam oferecer seus cursos baseado grupos de perfis de usuários mais propensos a contratá-los, visto que nessa situação o financiamento das atividades da empresa que gere a rede social advém da comercialização de espaços, e não de cobrança de taxas de empresas e profissionais.

Tem-se, portanto, com essas práticas e modelos de negócios o estabelecimento de um mercado em torno da exploração econômica do Big Data, que permite a consolidação de seu próprio ecossistema, no qual há interação entre os diversos agentes, permeados pela infraestrutura tecnológica que permite a coleta, análise e transferência de dados, e pelos consumidores, responsáveis por fornecer os dados que são a força motriz desse ecossistema.

A identificação desse ecossistema e dos agentes que dele participam é essencial para a definição do mercado de Big Data, em razão de que esse é fruto do intenso fluxo de dados e informações. Consequentemente, para uma melhor análise do ambiente concorrencial, faz-se necessário a identificação do mercado que se deseja abordar, reconhecer as especificidades dos diferentes mercados, para então realizar a análise mais apropriada. Observa-se que, na medida em que mais empresas passam a fazer uso dos dados, a compor esse ecossistema do Big Data, mais serão os setores impactados pelo uso de dados, e também será cada vez mais relevante para diferentes mercados possuir dados e ser capaz de convertê-los em informações úteis.

Nesse seguimento, a técnica mais utilizada pelos diversos autores que abordam o tema Big Data, é a definição do mercado relevante, em decorrência da visão mais ampla que tal delimitação proporciona. Por meio dessa análise, é possível identificar a principal característica, que são os efeitos de rede.

Os efeitos de rede são específicos do ambiente de atuação com grandes volumes de dados, isso porque deles decorrem os chamados feedback loops, que consistem em retornar com mais dados, as empresas que já possuem bastante dados. Dá-se tal situação porquanto as empresas que já são capazes de trabalhar com grandes dados e, por conseguinte, já estão aptas a oferecer melhores serviços aos seus usuários e possíveis 
anunciantes na plataforma, sendo capazes de aprimorar ainda mais sua capacidade.

Incorre de tal tendência do Big Data graves consequências para o ambiente concorrencial, sendo que àquela empresa, geralmente de grande porte, capaz de se beneficiar desses efeitos conseguirá se distanciar dos concorrentes, geralmente médias e pequenas empresas. Trata-se, portanto, de uma situação em que a diferença do acesso aos dados proporciona uma disparidade competitiva.

Reflete também essa diferença de acesso aos dados em outra característica bastante marcante no mercado de Big Data, que são as barreiras de entrada. Elas surgem a partir desse momento em que as empresas maiores e com acesso aos maiores volumes de dados impõem aos novos entrantes, comumente compostos por empresas menores, dificuldades de se estabelecer no mercado.

Assim, uma vez diante de tais características que torna viável uma possível ofensa ao ambiente concorrencial equilibrado, é que se faz necessária a aplicação das ferramentas previstas no âmbito do Direito Concorrencial. Ressalta-se que tal proteção deve ser realizada em diversos níveis, que contemplam a proteção do ambiente concorrencial propriamente dito, mas também o bem-estar do consumidor e sua privacidade.

Quanto ao ambiente concorrencial, essa se dá geralmente relacionada a três temas, a começar dos dados como fonte de poder de mercado, porque pode ser verificado que à medida que uma empresa possui mais dados será capaz de desequilibrar o mercado pelos já citados efeitos de rede e também pela imposição de barreiras de entrada a novos entrantes. O segundo fator é a transparência de dados, que se por um lado melhora o ambiente de competitividade ao permitir ao consumidor melhor comparação entre concorrentes, por outro lado pode configurar situações limitadoras da concorrência, ao tornar o ambiente mais passível de colusão. Por fim, têm-se os dados relacionados a condutas anticoncorrenciais, como cartéis digitais e situações em que os dados se tornam essenciais para possibilitar a entrada de agentes.

Já no âmbito do consumidor, faz-se necessário apontar que a proteção ao bem-estar do consumidor é um dos princípios inerentes a manutenção da ordem econômica, conforme destaca a Constituição Federal de 1988, isso porque o consumidor é o escopo da empresa, sem o consumo, não há mercado e sem mercado não há o desenvolvimento econômico e, consequentemente, o social. A proteção do consumidor se apresenta como 
necessária pela situação de vulnerabilidade que se encontra ante as empresas. Com relação ao consumidor do ponto de vista da era do Big Data, apresenta uma revolução, isso em razão do maior conhecimento que é possível ser obtido na medida em que as empresas estão aptas colher mais dados sobre esses indivíduos, reforçando a posição de vulnerabilidade desses ao aplicar possíveis condições abusivas, principalmente no tradeoff entre dados e acesso às plataformas.

Nesse sentido, não pode ser deixada a par do Direito Concorrencial a análise da privacidade dos dados desses consumidores, que são coletados pelas plataformas, já que passam a ter conotação econômica visto que a análise mais detalhada do perfil do usuário contribui para que as plataformas sejam capazes de comercializar anúncios melhor direcionados com base nessas informações. Logo, constituirá uma falha de mercado a ausência de maiores informações e/ou escolha de preferências quanto à privacidade dos dados que são divulgados e colhidos.

Está configurado, dessa maneira, que o Big Data é sim capaz de desequilibrar o ambiente concorrencial, e deve ser escopo de análise pelo Direito Concorrencial, que deve buscar maneiras de manter o ambiente da livre concorrência equilibrado, visto que o advento da grande quantidade de dados sendo coletadas e analisadas, em alta velocidade, o tempo todo é uma ameaça, tanto para o ambiente concorrencial de forma geral, quanto ao bem-estar dos consumidores, os principais afetados por uma coleta indiscriminada de dados.

À vista disso, deve haver no caso a caso, uma análise detalhada dos impactos causados e se os institutos jurídicos existentes são suficientes para sanar tal falha de mercado ou, caso contrário, sendo necessário o desenvolvimento de um arcabouço jurídico mais adequado à situação.

\section{REFERÊNCIAS BIBLIOGRÁFICAS}

ALLEN, Anita L. Protecting one's own privacy in a big data economy. In: Law, Privacy \& Technology Commentary Series. In: Harvard Law Review Forum, vol. 130. p. 71-78. Disponível em: < https://harvardlawreview.org/2016/12/protecting-ones-own-privacy-in-a-big-data-economy/>. Acesso em: 03 ago. 2018.

BAGNOLI, Vicente. Competition for the effectiveness of big data benefits. Max Planck Institute for Innovation and Competition, Munique, 2015. Disponível em:

<https://link.springer.com/article/10.1007/s40319-015-0382-4>. Acesso em: 09 abr. 2018. 
The big data relevant market. In: Concorrenza e Mercato, vol. 23, 2016. Disponível em: <https://papers.ssrn.com/sol3/papers.cfm?abstract_id=3064792〉. Acesso em: 09 abr. 2018.

CHEN, Min; MAO, Shiwen; ZHANG, Yin; LEUNG, Victor C.M. Big data: related technologies, challenges and future prospects. Springer, 2014. E-book. ISBN 978-3-319-06245-7. Disponível em: <http://epic.hust.edu.cn/minchen/min_paper/BigDataBook2014.pdf〉. Acesso em: 01 ago. 2018.

CURRY, Edward. The big data value chain: definitions, concepts, and theoretical approaches. In: CAVANILLAS, J.M. et al (Orgs.). New horizons for a data-driven economy. 2016. Disponível em: $\langle$ https://www.researchgate.net/publication/280625243_The_Big_Data_Value_Chain_Definitions_Co ncepts_and_Theoretical_Approaches>. Acesso em: 21 mai. 2018.

DE MAURO, Andrea; GRECO, Marco; GRIMALDI, Michele. A formal definition of big data based on its essential features. In: Library Review, Vol. 65 Issue: 3, pp. 122-135. 2016. Disponível em: <https://doi.org/10.1108/LR-06-2015-0061〉. Acesso em: 21 mai. 2018.

FONSECA, João Bosco Leopoldino da. Direito econômico. 8. ed. Rio de Janeiro: Forense, 2015. p. 342.

GLÓRIA, Daniel Firmato de Almeida. A livre concorrência como garantia do consumidor. Belo Horizonte: Del Rey; FUMEC, 2003.

GRAEF, Inge. Market definition and market power in data: the case of online platforms. World Competition 38, n. ${ }^{\circ}$ 4. 2015. p. 473-506. Disponível em:

<https://papers.ssrn.com/sol3/papers.cfm?abstract_id=2657732>. Acesso em: 03 ago. 2018.

KERBER, Wolfgang. Digital markets, data and privacy: competition law, consumer law and data protection. In: Gewerblicher Rechtsschutz und Urheberrecht. Internationaler Teil (GRUR Int) 2016, 639-647. Disponível em: 〈https://papers.ssrn.com/sol3/papers.cfm?abstract_id=2770479>. Acesso em: 03 ago. 2018.

LASSARE, Bruno; MUNDT, Andreas. Competition law and big data: the enforcer's view. Italian Antitrust Review, n. 1, p. 87-103, 2017. Disponível em:

<https://www.bundeskartellamt.de/SharedDocs/Publikation/EN/Fachartikel/Competition_Law_and_ Big_Data_The_enforcers_view.pdf?_blob=publicationFile\&v=2>. Acesso em: 07 jul. 2018.

ORGANIZAÇÃO PARA A COOPERAÇÃO E DESENVOLVIMENTO ECONOMICO (OCDE). Exploring data-driven innovation as a new source of growth: mapping the policy issues raised by "Big Data". OECD Digital Economy Papers, nº. 222, OECD Publishing, Paris. 2013. Disponível em: <http://dx.doi.org/10.1787/5k47zw3fcp43-en>. Acesso em: 21 mai. 2018.

Big data: bringing competition policy to the digital era. Background note by the Secretariat. 2016. Disponível em: <http://www.oecd-ilibrary.org/exploring-data-driven-innovationas-a-new-

sourceofgrowth_5k47zw3fcp43.pdf?contentType $=\% 2 \mathrm{fns} \% 2 \mathrm{fW}$ orkingPaper\&itemId $=\% 2 \mathrm{fcontent} \% 2 \mathrm{f}$ workingpaper\%2f5k47zw3fcp 43 -

en\&mimeType=application $\% 2 \mathrm{fpdf} \&$ containerItemId $=\% 2$ fcontent $\% 2$ fworkingpaperseries $\% 2 \mathrm{f} 207168$ $26 \&$ accessItemIds=\&option6=imprint \&value $6=\mathrm{http} \% 3 \mathrm{a} \% 2 \mathrm{f} \% 2$ foecd.metastore. ingenta.com $\% 2 \mathrm{fcont}$ ent\%2fimprint $\% 2$ foecd>. Acesso em: 21 mai. 2018. 
PFEIFFER, Roberto Augusto Castellanos. Defesa da concorrência e bem-estar do consumidor. 2010. Tese (Doutorado em Direito Econômico e Financeiro) - Faculdade de Direito, Universidade de São Paulo, 2010. doi: 10.11606/T.2.2010.tde-26092011-104134. Acesso em: 12 de out. de 2017.

PRESS, Gil. 12 big data definitions: what is yours?. Forbes, 2014. Disponível em: <https://www.forbes.com/sites/gilpress/2014/09/03/12-big-data-definitions-whatsyours/\#7cca0c1813ae>. Acesso em: 24 mai. 2018.

RUBINFELD, Daniel L.; GAL, Michal S. Access barriers to big data. Arizona Law Review. 2017. Disponível em: <https://awards.concurrences.com/IMG/pdf/ssrn-id2830586.pdf>. Acesso em: 01 ago. 2018.

SLOAN, Robert H.; WARNER, Richard. Big data and the "new" privacy tradeoff. Chicago-Kent College of Law Research Paper n.. 2013-33. 2013. Disponível em:

<https://papers.ssrn.com/sol3/papers.cfm?abstract_id=2306071〉. Acesso em: 01 ago. 2018. 